\title{
Dynamic Pricing and Supply Coordination with Reimbursement Contract under Random Yield and Demand
}

\author{
Guo Li, ${ }^{1}$ Lun Ran, ${ }^{1}$ Xiaohang Yue, ${ }^{2}$ and Zhaohua Wang ${ }^{1}$ \\ ${ }^{1}$ School of Management and Economics, Beijing Institute of Technology, Beijing 100081, China \\ ${ }^{2}$ Lubar School of Business, University of Wisconsin-Milwaukee, Milwaukee, WI 53201-0413, USA \\ Correspondence should be addressed to Guo Li; $\lg 4229682 @ 163 . c o m$
}

Received 22 May 2013; Revised 14 August 2013; Accepted 2 September 2013

Academic Editor: Tinggui Chen

Copyright (C) 2013 Guo Li et al. This is an open access article distributed under the Creative Commons Attribution License, which permits unrestricted use, distribution, and reproduction in any medium, provided the original work is properly cited.

This paper investigates the dynamic pricing and supply chain coordination in a decentralized system that consists of one supplier and one manufacturer, in which both the market demand and production yield are stochastic. We show that the centralized expected profit is jointly concave in the production quantity and order quantity when the price is ex-ante selected. We also derive the equilibrium strategies in the decentralized system and prove that the entire profit of supply chain is inevitably lower than that under centralized system. Based on this, we propose a reimbursement contract to coordinate the decentralized supply chain so as to achieve the maximized profit. It is worth mentioning that, under reimbursement contract, the equilibrium production and order quantities are irrelevant to the manufacturer's risk sharing coefficient but are only determined by the supplier's risk sharing coefficient.

\section{Introduction}

The intense competition in the semiconductor and electronics industry pushes the manufacturers to make substantial effort to reduce the production cost. For example, many manufacturers (e.g., Dell) may cut down the sales representatives or adopt the direct delivery. On the other hand, since the customer demand is getting more variable and price sensitive (e.g., purchasing laptops), the manufacturer also needs to carefully design the order quantity and pricing dynamically so as to extract more profit from the market.

In recent years, supply chain becomes more vulnerable to the influence from natural disasters, strikes, terrorist attacks, political instability, and other factors. In particular, after US "911" incident supply chain uncertainty and its associated potential losses are becoming much significant [1]. Some studies suggest that the frequency of catastrophic events is increasing year by year, and its harms are gradually rising up. Consequently, supply chain risk management raised attentions from both researchers and practitioners in operations management, for example, the multisourcing [25], alternative supply sources and backup production options [6-9], flexibility [10, 11], and supplier selection [12-14]. For a recent review of the supply-risk literature, please see the works by Tang and Abhijeet et al. [15, 16]. Generally, after investigation of 800 companies' disruption cases, Hendricks and Singhal find that the firms which experienced supply glitches suffer from declining operational performance and eroding shareholder value (e.g., the abnormal return on stock of such firms is negative $40 \%$ over three years) [17, 18].

The issue of linking risk assessment with risk mitigation for low-probability but high-consequence events such as disruptions of supplies is discussed by Kleindorfer and Saad. They provide 10 principles for specifying the sources of risk and assessment and mitigation of risk [19]. In addition, supply chains are also vulnerable to high-likelihood, low-impact operational risks that may arise from problems in supply and production process [20]. One common manifestation of this supply risk is random yield, in which the firm receives a random portion of the order placed with a supplier [21]. Though the production is strictly controlled, yield of the components can be uncertain due to the characteristics of process engineering or uncontrolled operations [22, 23]. For example, it is quite common in the LCD manufacturing industry in which the production yield is normally less than $50 \%$. In other words, manufacturers have to face both 
the random yields and random demand in today's competing environment.

Yano and Lee first give thorough review about single item single stage and multiitem multistage in an assembly system with lot sizing [24]. From then on, many scholars considered different random-yield problems from different aspects, and representatives referred to Gurnani et al. [25, 26], Gerchak and Wang [27], Li [28], Güler [29, 30], Tomlin [10], Giri [7], Tang et al. [31], and Gurnani et al. [25] explore a centralized assembly system facing random demand and random yield due to production yield losses. They formulate the exact cost functions with target level of finished products to assemble and the order quantity of the components from suppliers as the decision variables. In a multiperiod case, it is found that it might be optimal to order extra components for future use. Also the optimal ordering policy and assembly target level policy are shown to be an order-up-to type [25]. Gerchak and Wang consider coordination in a decentralized assembly systems with random demand. But they do not consider dynamic pricing and random yield [27]. Gurnani and Gerchak propose coordination in a decentralized assembly system with two suppliers and one manufacturer under uncertain component yield and determined demand. They consider that the component suppliers and manufacturer choose their production quantities and order quantities separately based solely on their own profit structure, but the selling price of final product is determined [26]. Based on Gurnani, Güler and Bilgiç and Keskin $(2008,2013)$ examine a decentralized assembly system with multisuppliers and one manufacturer under uncertain yield and demand. They compare wholesale price, buy-back, revenue share, quantity discount, and quantity flexibility contracts and propose two combined contracts to coordinate the assembly system. They also illustrate that the randomness in the yield does not change the coordination ability of the contracts but affects the values of the contract parameters $[29,30]$.

As to the dynamic pricing under random yield, there are few papers related to it. Li studies the joint inventory replenishment and pricing problem for production systems with random demand and yield [28]. Bakal and Akcali consider the effects of recovery yield rate on pricing decisions in reverse supply chains and determine the optimal acquisition price for the end-of-life products [32]. Tomlin and Wang investigate the production, pricing, down conversion, and allocation decisions in a two-class, stochastic-yield coproduction system. They establish that down conversion will not occur if prices are set optimally [10]. Giri considers a single-product single-period inventory model in which the retailer can source from one unreliable supplier with yield uncertainty and the other supplier which is more reliable but expensive [7]. Tang et al. consider a newsvendor problem with random demand and random yields, in which the price decision will be postponed and determined upon recognition of random yield and prior to realizing demand uncertainties [31].

To the best of our knowledge, most literature under random component yield has focused on centralized system where the price is ex-ante selected [33-37]. Some have studied establishing properties of the profit function of the chain and found the optimal order quantity but without pricing control [38]. Few have concentrated on dynamic pricing under random yield, but they consider different aspects from ours.

Consider that a manufacturer in a decentralized system faces the two-sided uncertainty: random yield and demand. Since lot sizing with uncertain yields is an important area in production/manufacturing systems [24], it is necessary to consider a decentralized system with lot sizing and dynamic pricing under both random yield and demand. To address these gaps between practice and the literature, we investigate the interactions among supply uncertainty, dynamic pricing, and supply chain coordination. In particular, we address the following questions.

(1) What are the optimal decisions at an exogenous price in the centralized system in case of uncertain yield and demand?

(2) What is the best solution to dynamic pricing in the centralized system?

(3) What are the manufacturer and supplier's best decisions in the decentralized system? How do they react to each other?

(4) How does the manufacturer in the decentralized system eliminate the uncertainty, achieve supply coordination, and maximize its profit?

To answer these questions, we construct a supply chain that consists of a single supplier and a single manufacturer. In Section 2, we investigate the basic model that is set as our benchmark. Section 3 provides the optimal decentralized decision for the supplier and manufacturer. Section 4 proposes the reimbursement contract to coordinate the supplier and manufacturer in the decentralized system. Section 5 reports the numerical study to illustrate our optimal decision and performance of our useful model. Section 6 concludes the paper with a summary of results.

\section{Model Formulation and Analysis}

2.1. Model Description. Consider a two-layer supply chain that contains one manufacturer and one supplier, who are both risk neutral and in purpose of maximizing the profit. The market demand is stochastic and price sensitive. Therefore, we use $y(p) \cdot \varepsilon$ to denote the demand function, in which $y(p)$ is the function of selling price $p$ and $\varepsilon$ is the random variable. Also, for simplicity we assume that $y(p) \cdot \varepsilon$ is equal to $y \varepsilon$. The manufacturer decides the selling price $p$ and also the order quantity of size $Q$ from the supplier. Given this order quantity $Q$, the supplier decides the production quantity $x$. However, since the production yield is also stochastic, the realized production quantity is $\alpha x$, wherein $\alpha$ is a random variable in $[0,1]$. Thus, the final size that will be delivered to the manufacturer is $\min (\alpha x, Q)$. The related parameters are denoted as follows.

$p$ : manufacturer's unit selling price for the final product,

$\pi_{m}$ : manufacturer's unit shortage cost for the final product, 
$c_{s}$ : supplier's unit production cost, $w$ : supplier's wholesale price,

$\Pi_{s}, \Pi_{m}, \Pi_{s c}$ : profit of supplier, manufacturer and supply chain, respectively,

$\mu_{\alpha}$ : mean value of $\alpha$,

$f(\cdot), F(\cdot)$ : probability density function and cumulative density function of $\varepsilon$, respectively,

$g(\cdot), G(\cdot)$ : probability density function and cumulative density function of $\alpha$, respectively.

Since $y(p)$ is sensitive to the final price, we use dynamic pricing to derive the optimal price. The manufacturer's profit function can be established as

$$
\begin{aligned}
\Pi_{m}= & p \cdot \min (\alpha x, Q, y \varepsilon) \\
& -\pi_{m}[y \varepsilon-\min (\alpha x, Q)]^{+} \\
& -w \cdot \min (\alpha x, Q) .
\end{aligned}
$$

The first term stands for the sales revenue, and the second term represents the penalty cost when the random demand exceeds the minimum value of random yield and order quantity. The third term is the purchasing cost for the manufacturer.

Similarly, the profit function for the supplier can be formulated as

$$
\Pi_{s}=w \cdot \min (\alpha x, Q)-c_{s} x .
$$

Note that in (2) the first term stands for sales revenue for the supplier and the second term is production cost.

Combining (1) and (2), we can obtain the profit function of supply chain, where

$$
\begin{aligned}
\Pi_{s c}= & p \cdot \min (\alpha x, Q, y \varepsilon) \\
& -\pi_{m}[y \varepsilon-\min (\alpha x, Q)]^{+}-c_{s} x .
\end{aligned}
$$

The basic models formulate a supply chain that is dominated by the manufacturer, in which the manufacturer will maximize supply chain profit and personal own profit under random demand and yield.

2.2. Optimal Decision and Dynamic Pricing for Centralized System. The expected profit for the centralized model is determined by $(Q, x)$, in which the selling price of final product is exogenously determined. The expected profit for the centralized system can be rewritten as follows:

$$
\begin{aligned}
& E\left(\Pi_{s c}\right) \\
& =p \cdot\left[\int_{0}^{\mathrm{Q} / x} \int_{\alpha x / y}^{\infty} \alpha x g(\alpha) f(\varepsilon) d \alpha d \varepsilon\right. \\
& +\int_{\mathrm{Q} / x}^{1} \int_{\mathrm{Q} / y}^{\infty} \mathrm{Qg}(\alpha) f(\varepsilon) d \alpha d \varepsilon \\
& \left.+\int_{0}^{\mathrm{Q} / y} \int_{y \varepsilon / x}^{1} y \varepsilon g(\alpha) f(\varepsilon) d \alpha d \varepsilon\right]
\end{aligned}
$$

$$
\begin{array}{r}
-\pi_{m}\left[\int_{0}^{\mathrm{Q} / x} \int_{\alpha x / y}^{\infty}(y \varepsilon-\alpha x) g(\alpha) f(\varepsilon) d \alpha d \varepsilon\right. \\
\left.+\int_{\mathrm{Q} / x}^{1} \int_{\mathrm{Q} / y}^{\infty} \mathrm{Qg}(\alpha) f(\varepsilon) d \alpha d \varepsilon\right]-c_{s} x .
\end{array}
$$

We subsequently obtain the optimal $\left(Q^{*}, x^{*}\right)$, namely, $\left(Q^{*}, x^{*}\right)=\arg \max E\left[\Pi_{s c}(Q, x)\right]$.

Proposition 1. The expected profit $E\left[\Pi_{c}(Q, x)\right]$ is jointly concave in $(Q, x)$. The optimal order quantity and production quantity are the unique solution to the following two equations:

$$
\begin{gathered}
\left(p+\pi_{m}\right) \int_{Q^{*} / x^{*}}^{1} \int_{Q^{*} / y}^{\infty} g(\alpha) f(\varepsilon) d \alpha d \varepsilon=0 \\
\left(p+\pi_{m}\right) \int_{0}^{Q^{*} / x^{*}} \int_{\alpha x^{*} / y}^{\infty} \alpha g(\alpha) f(\varepsilon) d \alpha d \varepsilon=c_{s} .
\end{gathered}
$$

Proof. Consider the following:

$$
\frac{\partial^{2} E\left(\Pi_{s c}\right)}{\partial Q^{2}}<0, \quad \frac{\partial^{2} E\left(\Pi_{s c}\right)}{\partial x^{2}}<0 .
$$

The Hessian matrix is as follows:

$$
H=\left(\begin{array}{ll}
\frac{\partial^{2} E\left(\Pi_{s c}\right)}{\partial Q^{2}} & \frac{\partial^{2} E\left(\Pi_{s c}\right)}{\partial Q \partial x} \\
\frac{\partial^{2} E\left(\Pi_{s c}\right)}{\partial x \partial Q} & \frac{\partial^{2} E\left(\Pi_{s c}\right)}{\partial x^{2}}
\end{array}\right)>0
$$

See Appendix for details.

Obviously (5) and (6) are solutions to (4), which are facilitated by the concavity of expected profit $E\left[\Pi_{c}(Q, x)\right]$. Based on the observation of (5) and (6), a proposition can be drawn as follows.

Proposition 2. The unique solution to (5) must satisfy $Q^{*}=$ $x^{*}$.

Proof. While $\left(p+\pi_{m}\right) \int_{Q^{*} / x^{*}}^{1} \int_{Q^{*} / y}^{\infty} g(\alpha) f(\varepsilon) d \alpha d \varepsilon \geq 0$, then $\int_{Q^{*} / x^{*}}^{1} \int_{Q^{*} / y}^{\infty} g(\alpha) f(\varepsilon) d \alpha d \varepsilon \geq 0$.

Only if $Q^{*}=x^{*}$, then $\int_{Q^{*} / x^{*}}^{1} \int_{Q^{*} / y}^{\infty} g(\alpha) f(\varepsilon) d \alpha d \varepsilon=$ $\int_{1}^{1} \int_{Q^{*} / y}^{\infty} g(\alpha) f(\varepsilon) d \alpha d \varepsilon=0$.

Note that $Q^{*}=x^{*}$, and (6) can be rewrite in another form as follows:

$$
\begin{aligned}
& \int_{0}^{Q^{*} / x^{*}} \int_{\alpha x^{*} / y}^{\infty} \alpha g(\alpha) f(\varepsilon) d \alpha d \varepsilon \\
& \quad=\int_{0}^{1} \int_{\alpha Q^{*} / y}^{\infty} \alpha g(\alpha) f(\varepsilon) d \alpha d \varepsilon \\
& =\frac{c_{s}}{p+\pi_{m}} .
\end{aligned}
$$




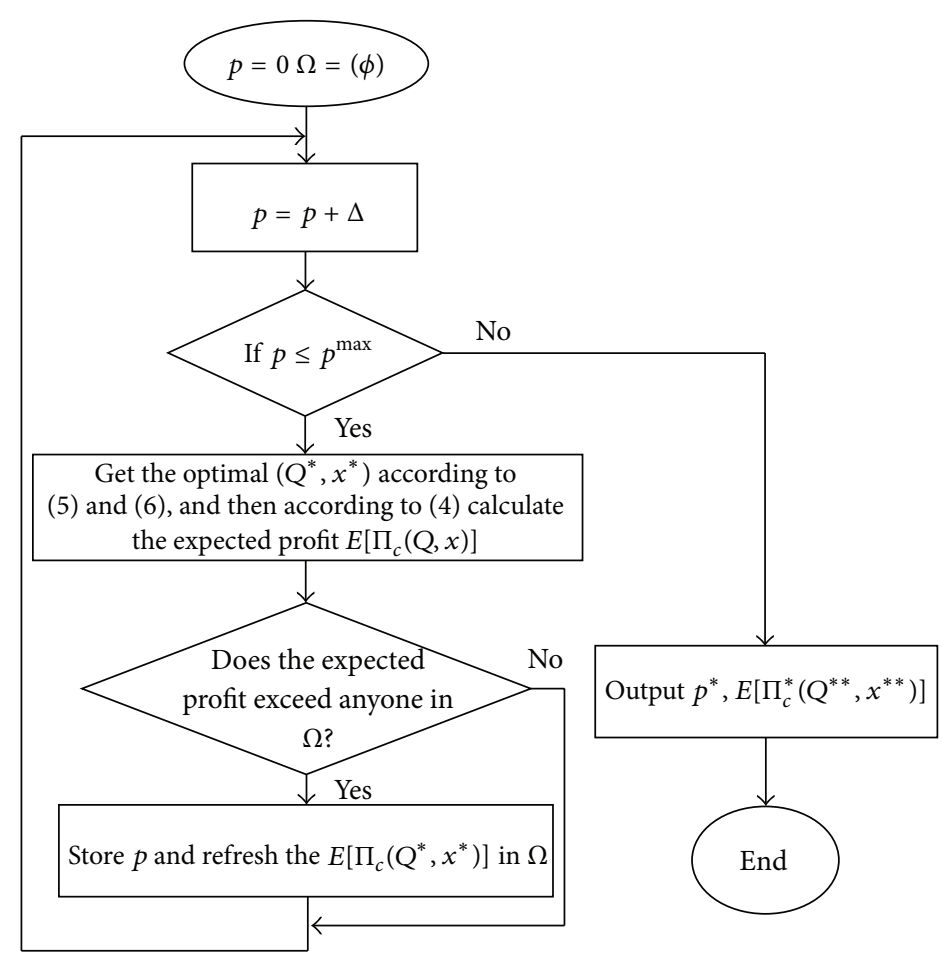

FIGURE 1: The algorithm process for dynamic pricing. $p^{\max }$, maximized price for a kind of product; $\Delta$, price markup coefficient; $E\left[\Pi_{c}^{*}(Q, x)\right]$, optimal expected profit of centralized system at the determined price $p ; E\left[\Pi_{c}^{*}\left(Q^{* *}, x^{* *}\right)\right]$, optimal expected profit of centralized system at the determined price $p^{*}$, while $p^{*} \in\left(0, p^{\max }\right]$.

This is similar to the equation developed by Shih [39] so that the optimal $Q^{*}$ can be obtained to satisfy (9).

As analyzed above, the expected profit $E\left[\Pi_{c}(Q, x)\right]$ for the centralized system is jointly concave in $(Q, x)$. Since the retail price is exogenously determined, we can derive a different expected profit $E\left[\Pi_{c}(Q, x)\right]$ under a different price $p$. In the next part, we will discuss the optimal expected profit $E\left[\Pi_{c}(Q, x)\right]$ under the optimal retail price. Therefore, we propose an algorithm to derive the optimal selling price $p$ that can maximize the expected profit $E\left[\Pi_{c}(Q, x)\right]$.

Step 1. Let $\Omega=(\phi)$ and $p=0$.

Step 2. Set $p=p+\Delta$ ( $\Delta$ is sufficiently small $)$.

Step 3. If $p \leq p^{\max }$, get the optimal $\left(Q^{*}, x^{*}\right)$ according to (5), and then calculate the expected profit $E\left[\Pi_{c}(Q, x)\right]$ according to (4). If not, then output the optimal $p^{*}$ and $E\left[\Pi_{c}^{*}\left(Q^{* *}, x^{* *}\right)\right]$.

Step 4. If the new expected profit $E\left[\Pi_{c}\left(Q^{*}, x^{*}\right)\right]$ exceeds the former one, store $p$ and refresh the $E\left[\Pi_{c}\left(Q^{*}, x^{*}\right)\right]$ in $\Omega$. Then go to Step 2. If not, return to Step 2 directly.

Step 5. Output the $\left(Q^{* *}, x^{* *}\right)$ which are corresponding to the optimal $p^{*}$ and $E\left[\Pi_{c}^{*}\left(Q^{* *}, x^{* *}\right)\right]$.

After Step 5, we can derive the optimal expected profit $E\left[\Pi_{c}^{*}\left(Q^{* *}, x^{* *}\right)\right]$ and the optimal price $p^{*}$. It also shows that the precision of $p^{*}$ can be ensured as long as $\Delta$ is sufficiently small. The detailed process is also illustrated in Figure 1.

\section{Decentralized Decision for Manufacturer and Supplier}

We then consider the decentralized system. As above mentioned, the manufacturer will adopt an optimal $p^{*}$ to maximize his expected profit $E\left[\Pi_{m}(Q)\right]$, and we start from the manufacturer's decision.

3.1. The Manufacturer's Decision for Order Quantity. According to (1), the manufacturer's expected profit $E\left[\Pi_{m}(Q)\right]$ under the optimal $p^{*}$ can be explained as follows:

$$
\begin{aligned}
& E\left[\Pi_{m}^{d}(\mathrm{Q})\right] \\
& =p^{*} \cdot\left[\int_{0}^{\mathrm{Q} / x} \int_{\alpha x / y}^{\infty} \alpha x g(\alpha) f(\varepsilon) d \alpha d \varepsilon\right. \\
& +\int_{\mathrm{Q} / x}^{1} \int_{\mathrm{Q} / y}^{\infty} \mathrm{Qg}(\alpha) f(\varepsilon) d \alpha d \varepsilon \\
& \left.+\int_{0}^{\mathrm{Q} / y} \int_{y \varepsilon / x}^{1} y \varepsilon g(\alpha) f(\varepsilon) d \alpha d \varepsilon\right] \\
& -\pi_{m}\left[\int_{0}^{\mathrm{Q} / x} \int_{\alpha x / y}^{\infty}(y \varepsilon-\alpha x) g(\alpha) f(\varepsilon) d \alpha d \varepsilon\right.
\end{aligned}
$$




$$
\begin{array}{r}
\left.+\int_{\mathrm{Q} / x}^{1} \int_{\mathrm{Q} / y}^{\infty} \operatorname{Qg}(\alpha) f(\varepsilon) d \alpha d \varepsilon\right] \\
-w\left[\int_{0}^{\mathrm{Q} / x} \alpha x g(\alpha) d \alpha+\int_{\mathrm{Q} / x}^{1} \operatorname{Qg}(\alpha) d \alpha\right] .
\end{array}
$$

Then take derivation of $E\left[\Pi_{m}^{d}(Q)\right]$ in $Q$, whose process is similar to Appendix. Let us assume that $\partial E\left[\Pi_{m}^{d}(Q)\right] / \partial Q=0$; then

$$
\begin{gathered}
\left(p^{*}+\pi_{m}\right) \int_{Q^{*} / x}^{1} \int_{Q^{*} / y}^{\infty} g(\alpha) f(\varepsilon) d \alpha d \varepsilon \\
-w \int_{Q^{*} / x}^{1} g(\alpha) d \alpha=0 .
\end{gathered}
$$

Equation (11) is the solution to the manufacturer's expected profit $E\left[\Pi_{m}(Q)\right]$ when the supplier's production quantity is certain.

3.2. The Supplier's Decision for Production Quantity. According to (2), the supplier's expected profit $E\left[\Pi_{s}(x)\right]$ can be explained as follows:

$$
\begin{aligned}
& E\left[\Pi_{s}^{d}(\mathrm{Q})\right] \\
& =w\left[\int_{0}^{\mathrm{Q} / x} \alpha x g(\alpha) d \alpha+\int_{\mathrm{Q} / x}^{1} \mathrm{Qg}(\alpha) d \alpha\right] \\
& \quad-c_{s} \cdot x .
\end{aligned}
$$

$E\left[\Pi_{s}^{d}(x)\right]$ is differential in $x$, where

$$
\begin{aligned}
& \frac{\partial E\left[\Pi_{s}^{d}(x)\right]}{\partial x} \\
& =w\left[\int_{0}^{\mathrm{Q} / x} \alpha g(\alpha) d \alpha+Q \cdot g\left(\frac{Q}{x}\right)\left(-\frac{Q}{x^{2}}\right)\right. \\
& \left.\quad-Q \cdot g\left(\frac{Q}{x}\right)\left(-\frac{Q}{x^{2}}\right)\right]-c_{s} \\
& =w \int_{0}^{Q / x} \alpha g(\alpha) d \alpha-c_{s} .
\end{aligned}
$$

Let us assume that $\partial E\left[\Pi_{s}^{d}(x)\right] / \partial x=0$; then

$$
w \int_{0}^{\mathrm{Q} / x^{*}} \alpha g(\alpha) d \alpha-c_{s}=0 .
$$

Equation (14) is the solution to maximizing the supplier's expected profit $E\left[\Pi_{s}(Q)\right]$.

3.3. Analysis of Nash Equilibrium between Manufacturer and Supplier. From (11) and (14), we can derive $\left(Q^{n e}, x^{\text {ne }}\right)$ so as to derive the following results.

Proposition 3. There exists a unique Nash equilibrium solution $\left(Q^{n e}, x^{n e}\right)$ to the decentralized system between the manufacturer and the supplier.
Proof. Consider two differentiable functions $f(x)$ and $g(x)$. If $f^{\prime}(x)-g^{\prime}(x)>0$ or $f^{\prime}(x)-g^{\prime}(x)<0$, then there exists $x^{*}$ which makes $f\left(x^{*}\right)=g\left(x^{*}\right)$ for all $x$ (see Gurnani and Gerchak, [26, Proposition 2.1]).

Therefore,

$$
\begin{aligned}
& \text { set } f_{1}(\mathrm{Q}, x) \\
& =\left(p^{*}+\pi_{m}\right) \int_{Q^{*} / x}^{1} \int_{Q^{*} / y}^{\infty} g(\alpha) f(\varepsilon) d \alpha d \varepsilon \\
& -w \int_{Q^{*} / x}^{1} g(\alpha) d \alpha, \\
& f_{2}(Q, x) \\
& =w \int_{0}^{\mathrm{Q} / x} \alpha g(\alpha) d \alpha-c_{s}, \\
& \frac{\partial f_{1}(Q, x)}{\partial x} \\
& =-\left(p^{*}+\pi_{m}\right) \int_{\mathrm{Q} / y}^{\infty} g\left(\frac{Q}{x}\right) \\
& \cdot\left(-\frac{Q}{x^{2}}\right) f(\varepsilon) d \varepsilon \\
& -w \cdot g\left(\frac{Q}{x}\right) \cdot\left(-\frac{Q}{x^{2}}\right), \\
& \frac{\partial f_{2}(Q, x)}{\partial x} \\
& =w \cdot \frac{Q}{x} \cdot g\left(\frac{Q}{x}\right)\left(-\frac{Q}{x^{2}}\right), \\
& \frac{\partial f_{1}(Q, x)}{\partial x}-\frac{\partial f_{2}(Q, x)}{\partial x} \\
& =\left(p^{*}+\pi_{m}\right) \int_{Q / y}^{\infty} \frac{Q}{x^{2}} \cdot g\left(\frac{Q}{x}\right) f(\varepsilon) d \varepsilon \\
& +w \cdot \frac{Q}{x^{2}} \cdot g\left(\frac{Q}{x}\right)+w \cdot \frac{Q^{2}}{x^{3}} \cdot g\left(\frac{Q}{x}\right)>0 .
\end{aligned}
$$

We show that Nash equilibrium always exists for concavepayoff-functions games like ours (see Friedman, [40, Theorem 2.4]); the reaction curves will intersect exactly once and hence the Nash equilibrium is unique.

According to Yano and Lee [24], the expected profit of supply chain under this Nash equilibrium, namely, $E\left[\Pi_{s c}^{d}\left(Q^{n e}, x^{n e}\right)\right]$, is less than centralized expected profit of supply chain $E\left[\Pi_{c}^{*}(Q, x)\right]$. So it is necessary for the decentralized system to achieve the coordination and obtain the same profit as the centralized system. Later, a mechanism will be proposed for the decentralized system to achieve the same profit as the centralized system. 


\section{Reimbursement Contract}

As analyzed above, the Nash game between the manufacturer and the supplier in the decentralized system undermines the supply chain's performance, which is caused by the double marginalization. Therefore, to achieve the profit of centralized system, an effective contract should be proposed to coordinate the supplier and the manufacturer in the decentralized system.

Note that there are many contracts which can coordinate supply chain, such as buy-back contract, revenue-sharing contract, quantity discount contract, and sales rebate contract, in which most of them are used by the supplier to encourage the retailers to order more. Therefore, these are not applicable to our case that contains both random yield and demand. In contrast, we propose a new contract to share the risk of random yield and demand and define it as reimbursement contract. That is, if the supplier's random yield exceeds the manufacturer's order quantity, the manufacturer shares its risk and gives reimbursement $\theta_{1}$ to the supplier. When the manufacturer's random demand exceeds the order quantity, the supplier share its risk and give reimbursement $\theta_{2}$ to the manufacturer. Therefore, $\theta_{1}$ and $\theta_{2}$ can be defined as

$$
\begin{aligned}
& \theta_{1}=m[\alpha x-Q]^{+} \\
& \theta_{2}=s[y \varepsilon-\alpha x]^{+} .
\end{aligned}
$$

We define $m$ as the manufacturer's risk sharing coefficient for the supplier's excessive production, and $s$ stands for the supplier's risk sharing coefficient for the manufacturer's excessive random demand. It is obvious to show that $m<w, s<$ $\pi_{m}$. Thus, the extra transfer payment under reimbursement contract is $T^{r}$; then

$$
\begin{aligned}
T^{r} & =\theta_{1}-\theta_{2} \\
& =m[\alpha x-Q]^{+}-s[y \varepsilon-\alpha x]^{+} .
\end{aligned}
$$

The expected profit of supplier and manufacturer can be rewritten as follows:

$$
\begin{aligned}
E\left(\Pi_{m}^{r}\right)= & p^{*} \cdot E[\min (\alpha x, Q, y \varepsilon)] \\
& -E\left\{\pi_{m}[y \varepsilon-\min (\alpha x, Q)]^{+}\right\} \\
& -w \cdot E[\min (\alpha x, Q)]-E\left(T^{r}\right) \\
E\left(\Pi_{s}^{r}\right)=w & \cdot E[\min (\alpha x, Q)]-c_{s} x+E\left(T^{r}\right) .
\end{aligned}
$$

Under this reimbursement contract, the manufacturer will use the optimal price of the centralized supply chain as the selling price, and the supplier will also maximize his expected profit as

$$
\begin{aligned}
\frac{\partial E\left[\Pi_{m}^{r}\right]}{\partial Q}= & \left(p^{*}+\pi_{m}\right) \int_{Q^{* *} / x^{* *}}^{1} \int_{Q^{* *} / y}^{\infty} g(\alpha) f(\varepsilon) d \alpha d \varepsilon \\
& -w \int_{Q^{* *} / x^{* *}}^{1} g(\alpha) d \alpha \\
& -m \int_{Q^{* *} / x^{* *}}^{1}\left(\alpha x^{* *}-Q^{* *}\right) g(\alpha) d \alpha,
\end{aligned}
$$

$$
\begin{aligned}
\frac{\partial E\left[\Pi_{s}^{r}\right]}{\partial x}= & w \int_{0}^{Q^{* *} / x^{* *}} \alpha g(\alpha) d \alpha \\
& +\widehat{m} \int_{Q^{* *} / x^{* *}}^{1} \alpha g(\alpha) d \alpha \\
& +\widehat{s} \int_{0}^{1} \int_{\alpha x^{* *} / y}^{\infty} \alpha g(\alpha) f(\varepsilon) d \alpha d \varepsilon-c_{s} .
\end{aligned}
$$

Let $\partial E\left[\Pi_{m}^{r}\right] / \partial Q=0, \partial E\left(\Pi_{s}^{r}\right) / \partial x=0, Q^{* *}=x^{* *}$ from Proposition 2. Then (19) can be simplified as

$$
\begin{aligned}
& w \mu_{\alpha}+\widehat{s} \int_{0}^{1} \int_{\alpha x^{* *} / y}^{\infty} \alpha g(\alpha) f(\varepsilon) d \alpha d \varepsilon-c_{s}=0 \\
& \text { s.t. } \quad E\left(\Pi_{m}^{r}\right) \geq E\left(\Pi_{m}^{n e}\right), \quad E\left(\Pi_{s}^{r}\right) \geq E\left(\Pi_{s}^{n e}\right) .
\end{aligned}
$$

Equation (20) is the solution to coordinate the decentralized supply chain and $\widehat{s}$ should be adjusted to satisfy the previous equation. From (20), there exists unique $s^{*}$ to satisfy the equation. Though (20) does not contain $\widehat{m}, \widehat{m}$ is also effective and its value changes the final profit between the supplier and the manufacturer. Under this reimbursement contract, the decentralized supply chain can achieve the performance of centralized supply chain.

\section{Numerical Analysis}

In this section, we provide numerical illustrations of optimal lot-sizing, production quantity, and dynamic pricing under different $\Delta$. We assume that random variable $\varepsilon$ of demand obeys the normal distribution with $\mu_{\varepsilon}=1, \sigma_{\varepsilon}=0.25$. The random variable $\alpha$ of supply has a uniform distribution of yield taking values in $(0,1)$. Then the demand function can be assumed as $y(p)=a \cdot p^{-b}$, while $b>1$. This means that the demand for the final product is elastic. First we will consider optimal decision and dynamic piecing for centralized system, and then supply coordination will be analyzed.

5.1. Dynamic Pricing for Centralized Supply Chain. According to (4), (5), and (6), the optimal order quantities, production quantities, and the expected profit of centralized supply chain are depicted in Table 1 for 12 cases under determined price.

Table 1 shows under different prices that there exists the optimal order quantity, production quantity, and the expected profit in the centralized supply chain. As shown in the Figure 2, when price rises up to 5 the profit of centralized supply chain is maximized. One might wonder whether the price 5 is the optimal price for this system. Therefore, we then explore the optimal price for this centralized supply chain by using our algorithm put forward above. The algorithm can be programmed in MATLAB 7. As in this specific case, the optimal expected profit can be calculated, that is the 559.08, and the error deviating from standard expected profit can be estimated.

From Table 2, when $\Delta$ becomes smaller, the error also becomes smaller from the whole view. When $\Delta=0.1$, the error of the optimal expected profit for centralized system 


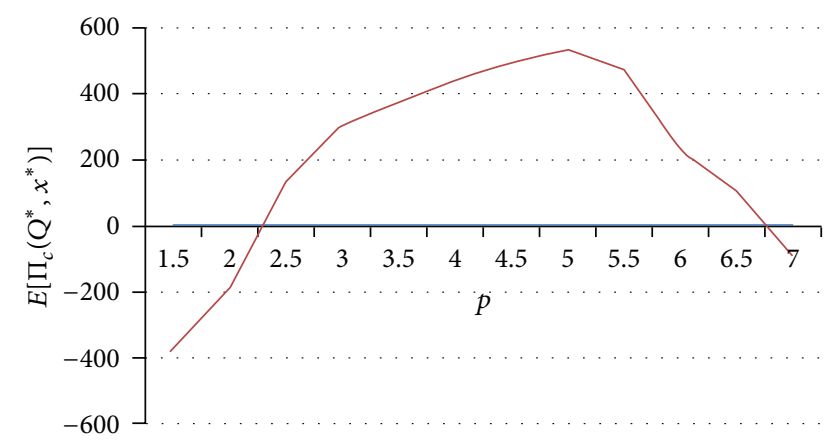

Figure 2: Optimal profits in the centralized system with different determined prices.

TABLE 1: Centralized solution under different determined prices.

\begin{tabular}{lcccccc}
\hline Case & $p$ & $\pi$ & $c$ & $Q^{*}$ & $x^{*}$ & $E\left[\Pi_{c}\left(Q^{*}, x^{*}\right)\right]$ \\
\hline 1 & 1.5 & 1 & 1 & 231.43 & 231.43 & -379.3 \\
2 & 2 & 1 & 1 & 351.17 & 351.17 & -193.59 \\
3 & 2.5 & 1 & 1 & 424.86 & 424.86 & 132.84 \\
4 & 3 & 1 & 1 & 498.57 & 498.57 & 295.71 \\
5 & 3.5 & 1 & 1 & 538.72 & 538.72 & 373.83 \\
6 & 4 & 1 & 1 & 623.47 & 623.47 & 441.16 \\
7 & 4.5 & 1 & 1 & 638.31 & 638.31 & 495.93 \\
8 & 5 & 1 & 1 & 659.29 & 659.29 & 532.46 \\
9 & 5.5 & 1 & 1 & 677.51 & 677.51 & 472.17 \\
10 & 6 & 1 & 1 & 693.22 & 693.22 & 230.96 \\
11 & 6.5 & 1 & 1 & 721.83 & 721.83 & 105.58 \\
12 & 7 & 1 & 1 & 749.54 & 749.54 & -93.07 \\
\hline
\end{tabular}

TABLE 2: The optimal price under different $\Delta$.

\begin{tabular}{lcccccc}
\hline Case & $\Delta$ & $p$ & $Q^{*}$ & $x^{*}$ & $E\left[\Pi_{c}^{*}\left(Q^{* *}\right)\right]$ & Error \\
\hline 1 & 0.1 & 4.8 & 647.52 & 647.52 & 534.83 & $4.34 \%$ \\
2 & 0.05 & 4.85 & 652.68 & 652.68 & 552.14 & $1.25 \%$ \\
3 & 0.001 & 4.854 & 654.41 & 654.41 & 556.83 & $0.40 \%$ \\
4 & 0.0005 & 4.8535 & 655.11 & 655.11 & 558.26 & $0.15 \%$ \\
5 & 0.00001 & 4.85346 & 655.25 & 655.25 & 559.01 & $0.01 \%$ \\
6 & 0.000005 & 4.853458 & 655.36 & 655.36 & 559.09 & $0.0003 \%$ \\
\hline
\end{tabular}

is $4.34 \%$. As $\Delta$ decreases, the error of the optimal expected profit for the centralized system also drops. When $\Delta=$ 0.000005 , the error of the optimal expected profit drops to $0.0003 \%$, which is fairly small. The result can be drawn that the precision of this algorithm can be ensured as long as $\Delta$ are sufficiently small. Therefore the optimal price for this centralized supply chain can be obtained through this algorithm.

\subsection{Supply Coordination Based on Reimbursement Contract.} As supply chain is dominated by the manufacturer, he will use the optimal price for decentralized supply chain. Suppose that the optimal price is $p^{*}=4.85346$ (see Table 2, case 5). Then different coordinated ways and parameters are compared in Table 3.

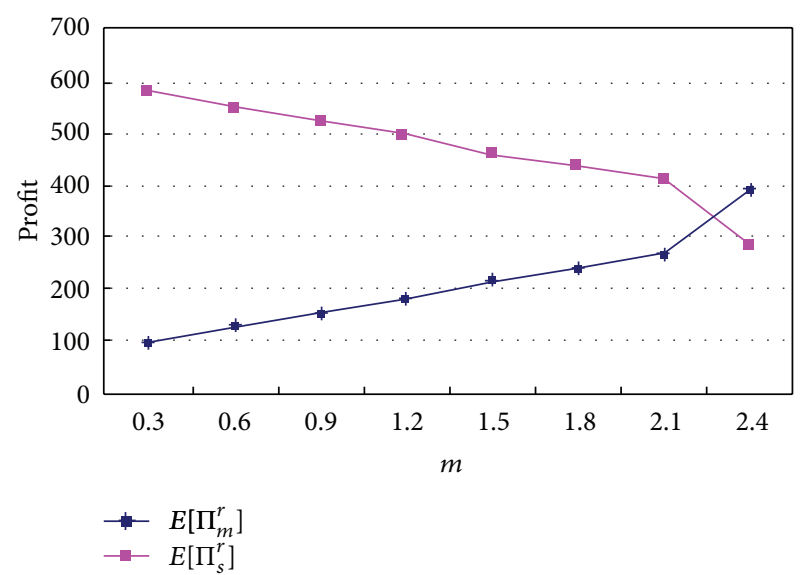

FIgURE 3: The relation between $m, E\left[\Pi_{s}^{r}\right]$, and $E\left[\Pi_{m}^{r}\right]$.

As illustrated in Table 3, decentralized supply chain can be coordinated based on reimbursement contract and achieve the same performance as the centralized supply chain. It should be pointed out that $E\left(\Pi_{m}^{r}\right) \geq E\left(\Pi_{m}^{n e}\right), E\left(\Pi_{s}^{r}\right) \geq E\left(\Pi_{s}^{n e}\right)$. So cases 1 and 8 in Table 3 are not acceptable by the supplier or the manufacturer because under reimbursement contract his profit is less than that under Nash equilibrium. It can be observed that $s$ is unique and determined but $m$ can be changed. Then the relation between $m$ and $E\left[\Pi_{s}^{r}\right], E\left[\Pi_{m}^{r}\right]$ can be shown in Figure 3.

From Figure 3, $m$ has its range to ensure $E\left(\Pi_{m}^{r}\right) \geq E\left(\Pi_{m}^{n e}\right)$, $E\left(\Pi_{s}^{r}\right) \geq E\left(\Pi_{s}^{n e}\right)$. And this case shows that this contract can coordinate supply chain properly.

\section{Conclusion}

In this paper, we study the coordination mechanism in a decentralized system that consists of one manufacturer and one supplier under both random yield and random demand. We consider two scenarios in which the retail price can be either exogenously or endogenously determined. In particular, we propose an algorithm to derive the optimal price in the centralized model. This sets our benchmark to compare the decentralized decisions for the supplier and the manufacturer. Based on this, we finally propose the reimbursement contract to coordinate decentralized supply chain. The major implications in this paper are concluded as follows.

(1) The expected profit $E\left[\Pi_{c}(Q, x)\right]$ is jointly concave in $(Q, x)$ when the price is exogenously determined. Moreover, the optimal production quantity can be equal to the optimal order quantity when the system is integrated.

(2) There exists a unique Nash equilibrium solution $\left(Q^{n e}, x^{n e}\right)$ for the manufacturer and supplier in the decentralized system between. Thus, double marginalization significantly undermines the channel's efficiency compared to the centralized system.

(3) A reimbursement contract is proposed to perfectly coordinate the channel. In particular, parameter $\widehat{s}$ should be adjusted to coordinate the decentralized 
TABLE 3: Comparison of supply chain under different conditions.

\begin{tabular}{|c|c|c|c|c|c|c|c|c|c|c|c|c|c|c|c|c|}
\hline \multirow{2}{*}{$p^{*}$} & \multicolumn{4}{|c|}{ Centralized supply chain } & \multicolumn{5}{|c|}{ Supply chain under Nash equilibrium } & \multicolumn{7}{|c|}{ Coordinate supply chain based on reimbursement contract } \\
\hline & $Q^{* *}$ & $x^{* *}$ & $E\left[\Pi_{s c}^{*}\right]$ & $w$ & $Q^{n e}$ & $x^{n e}$ & $E\left[\Pi_{s}^{n e}\right]$ & $E\left[\Pi_{m}^{n e}\right]$ & $E\left[\Pi_{s c}^{n e}\right]$ & $m$ & $s$ & $Q^{* *}$ & $x^{* *}$ & $E\left[\Pi_{s}^{r}\right]$ & & $E\left[\Pi_{s c}^{r}\right]$ \\
\hline & & 655.25 & & 2.5 & 662.94 & & & & & & & & & & & 577.13 \\
\hline & & 655.25 & 677 & 2.5 & 4 & 737. & & & & & & & & & & 7713 \\
\hline & & & & 2.5 & & & & & & & & & & & & \\
\hline & & & & 2.5 & & & & & & & & & & & & 77.13 \\
\hline & 5.25 & & & 2.5 & 4 & 737 & & & & & & & & & & 77.13 \\
\hline & 5525 & 655.25 & & 2.5 & 662.94 & 737.41 & & & & & & & & & & 577.13 \\
\hline & 5.25 & & & 2.5 & 662.94 & 737.41 & & & & & & & & & & 677.13 \\
\hline 853 & 655.25 & 55.25 & 677.13 & 2.5 & 662.94 & 737.41 & 136.87 & 292.96 & 429.83 & 2.4 & 0.79 & 655.25 & 655.25 & 392.17 & 284.96 & 677.13 \\
\hline
\end{tabular}

supply chain and there exists unique $s^{*}$. In contrast, $\widehat{m}$ cannot coordination channel directly, and it becomes effective and changes the profit ratio between the supplier and manufacturer.

\section{Appendix}

\section{Proof of Proposition 1}

$$
\begin{gathered}
\frac{\partial E\left(\Pi_{s c}\right)}{\partial Q} \\
=p \cdot\left\{\frac{\partial}{\partial Q}\left[\int_{0}^{Q / x} \int_{\alpha x / y}^{\infty} \alpha x g(\alpha) f(\varepsilon) d \alpha d \varepsilon\right]\right. \\
+\frac{\partial}{\partial Q}\left[\int_{Q / x}^{1} \int_{Q / y}^{\infty} Q g(\alpha) f(\varepsilon) d \alpha d \varepsilon\right] \\
\left.+\frac{\partial}{\partial Q}\left[\int_{0}^{Q / y} \int_{y \varepsilon / x}^{1} y \varepsilon g(\alpha) f(\varepsilon) d \alpha d \varepsilon\right]\right\} \\
-\pi_{m}\left\{\frac{\partial}{\partial Q}\left[\int_{0}^{Q / x} \int_{\alpha x / y}^{\infty}(y \varepsilon-\alpha x) g(\alpha) f(\varepsilon) d \alpha d \varepsilon\right]\right. \\
\left.+\frac{\partial}{\partial Q}\left[\int_{Q / x}^{1} \int_{Q / y}^{\infty}(y \varepsilon-Q) g(\alpha) f(\varepsilon) d \alpha d \varepsilon\right]\right\},
\end{gathered}
$$

where

$$
\begin{gathered}
\frac{\partial}{\partial Q}\left[\int_{0}^{Q / x} \int_{\alpha x / y}^{\infty} \alpha x g(\alpha) f(\varepsilon) d \alpha d \varepsilon\right] \\
=\int_{Q / y}^{\infty} \frac{Q}{x} \cdot g\left(\frac{Q}{x}\right) f(\varepsilon) d \varepsilon
\end{gathered}
$$

$$
\begin{gathered}
\frac{\partial}{\partial Q}\left[\int_{\mathrm{Q} / x}^{1} \int_{\mathrm{Q} / y}^{\infty} Q g(\alpha) f(\varepsilon) d \alpha d \varepsilon\right] \\
=\int_{\mathrm{Q} / x}^{1} \int_{\mathrm{Q} / y}^{\infty} g(\alpha) f(\varepsilon) d \alpha d \varepsilon \\
\quad-\int_{\mathrm{Q} / x}^{1} \frac{Q}{y} \cdot f\left(\frac{\mathrm{Q}}{y}\right) g(\alpha) d \alpha \\
-\int_{\mathrm{Q} / y}^{1} \frac{\mathrm{Q}}{x} \cdot g\left(\frac{\mathrm{Q}}{x}\right) f(\varepsilon) d \varepsilon,
\end{gathered}
$$

$$
\begin{gathered}
\frac{\partial}{\partial Q}\left[\int_{0}^{Q / y} \int_{y \varepsilon / x}^{1} y \varepsilon g(\alpha) f(\varepsilon) d \alpha d \varepsilon\right] \\
=\int_{Q / x}^{1} \frac{Q}{y} \cdot f\left(\frac{Q}{y}\right) g(\alpha) d \alpha,
\end{gathered}
$$$$
\frac{\partial}{\partial Q}\left[\int_{0}^{Q / x} \int_{\alpha x / y}^{\infty}(y \varepsilon-\alpha x) g(\alpha) f(\varepsilon) d \alpha d \varepsilon\right]
$$$$
=\int_{Q / y}^{\infty}(y \varepsilon-\alpha x) \cdot \frac{1}{x} g\left(\frac{Q}{x}\right) f(\varepsilon) d \varepsilon,
$$$$
\frac{\partial}{\partial Q}\left[\int_{Q / x}^{1} \int_{Q / y}^{\infty}(y \varepsilon-Q) g(\alpha) f(\varepsilon) d \alpha d \varepsilon\right]
$$$$
=-\int_{\mathrm{Q} / x}^{1} \int_{\mathrm{Q} / y}^{\infty} g(\alpha) f(\varepsilon) d \alpha d \varepsilon
$$$$
-\int_{\mathrm{Q} / y}^{\infty}(y \varepsilon-\alpha x) \cdot \frac{1}{x} g\left(\frac{Q}{x}\right) f(\varepsilon) d \varepsilon,
$$

$\frac{\partial E\left(\Pi_{s c}\right)}{\partial Q}$

$$
\begin{aligned}
& =\left(p+\pi_{m}\right) \int_{Q / x}^{1} \int_{Q / y}^{\infty} g(\alpha) f(\varepsilon) d \alpha d \varepsilon \\
& =\left(p+\pi_{m}\right) \bar{G}\left(\frac{Q}{x}\right) \bar{F}\left(\frac{Q}{y}\right),
\end{aligned}
$$




$$
\begin{aligned}
& \frac{\partial^{2} E\left(\Pi_{s c}\right)}{\partial Q^{2}} \\
& =-\left(p+\pi_{m}\right) \\
& \times\left[\frac{1}{x} g\left(\frac{Q}{x}\right) \bar{F}\left(\frac{Q}{y}\right)+\frac{1}{y} f\left(\frac{Q}{y}\right) \bar{G}\left(\frac{Q}{x}\right)\right]<0, \\
& \frac{\partial E\left(\Pi_{s c}\right)}{\partial x} \\
& =p \cdot\left\{\frac{\partial}{\partial x}\left[\int_{0}^{Q / x} \int_{\alpha x / y}^{\infty} \alpha x g(\alpha) f(\varepsilon) d \alpha d \varepsilon\right]\right. \\
& +\frac{\partial}{\partial x}\left[\int_{Q / x}^{1} \int_{Q / y}^{\infty} Q g(\alpha) f(\varepsilon) d \alpha d \varepsilon\right] \\
& \left.+\frac{\partial}{\partial x}\left[\int_{0}^{\mathrm{Q} / y} \int_{y \varepsilon / x}^{1} y \varepsilon g(\alpha) f(\varepsilon) d \alpha d \varepsilon\right]\right\} \\
& -\pi_{m}\left\{\frac{\partial}{\partial x}\left[\int_{0}^{\mathrm{Q} / x} \int_{\alpha x / y}^{\infty}(y \varepsilon-\alpha x) g(\alpha) f(\varepsilon) d \alpha d \varepsilon\right]\right. \\
& \left.+\frac{\partial}{\partial x}\left[\int_{Q / x}^{1} \int_{Q / y}^{\infty}(y \varepsilon-Q) g(\alpha) f(\varepsilon) d \alpha d \varepsilon\right]\right\}-c_{s} \text {, }
\end{aligned}
$$

where

$$
\begin{aligned}
& \frac{\partial}{\partial x}\left[\int_{0}^{Q / x} \int_{\alpha x / y}^{\infty} \alpha x g(\alpha) f(\varepsilon) d \alpha d \varepsilon\right] \\
& =\int_{0}^{\mathrm{Q} / x} \int_{\alpha x / y}^{\infty} \alpha g(\alpha) f(\varepsilon) d \alpha d \varepsilon \\
& -\int_{0}^{\mathrm{Q} / x} \frac{\alpha^{2} x}{y} f\left(\frac{\alpha x}{y}\right) g(\alpha) d \alpha \\
& -\int_{Q / y}^{\infty} \frac{Q^{2}}{x^{2}} g\left(\frac{Q}{x}\right) f(\varepsilon) d \varepsilon, \\
& \frac{\partial}{\partial x}\left[\int_{Q / x}^{1} \int_{Q / y}^{\infty} Q g(\alpha) f(\varepsilon) d \alpha d \varepsilon\right] \\
& =\int_{\mathrm{Q} / y}^{\infty} \frac{\mathrm{Q}^{2}}{x^{2}} g\left(\frac{\mathrm{Q}}{x}\right) f(\varepsilon) d \varepsilon, \\
& \frac{\partial}{\partial x}\left[\int_{0}^{\mathrm{Q} / y} \int_{y \varepsilon / x}^{1} y \varepsilon g(\alpha) f(\varepsilon) d \alpha d \varepsilon\right] \\
& =\int_{0}^{\mathrm{Q} / y} \frac{y^{2} \varepsilon^{2}}{x^{2}} f\left(\frac{y \varepsilon}{x}\right) f(\varepsilon) d \varepsilon \\
& \frac{\partial}{\partial x}\left[\int_{0}^{Q / x} \int_{\alpha x / y}^{\infty}(y \varepsilon-\alpha x) g(\alpha) f(\varepsilon) d \alpha d \varepsilon\right] \\
& =-\int_{0}^{\mathrm{Q} / x} \int_{\alpha x / y}^{\infty} \alpha g(\alpha) f(\varepsilon) d \alpha d \varepsilon \\
& -\int_{\mathrm{Q} / y}^{\infty} \frac{\mathrm{Q}}{x^{2}}(y \varepsilon-Q) g\left(\frac{\mathrm{Q}}{x}\right) f(\varepsilon) d \varepsilon,
\end{aligned}
$$

$$
\begin{aligned}
& \frac{\partial}{\partial x}\left[\int_{Q / x}^{1} \int_{Q / y}^{\infty}(y \varepsilon-Q) g(\alpha) f(\varepsilon) d \alpha d \varepsilon\right] \\
& =\int_{Q / y}^{\infty} \frac{Q}{x^{2}}(y \varepsilon-Q) g\left(\frac{Q}{x}\right) f(\varepsilon) d \varepsilon, \\
& \frac{\partial E\left(\Pi_{s c}\right)}{\partial x} \\
& =\left(p+\pi_{m}\right) \int_{0}^{Q / x} \int_{\alpha x / y}^{\infty} \alpha g(\alpha) f(\varepsilon) d \alpha d \varepsilon-c_{s},
\end{aligned}
$$$$
\frac{\partial^{2} E\left(\Pi_{s c}\right)}{\partial x^{2}}
$$$$
=-\left(p+\pi_{m}\right)
$$$$
\times\left[\int_{Q / y}^{\infty} \frac{Q^{2}}{x^{3}} g\left(\frac{Q}{x}\right) f(\varepsilon) d \varepsilon\right.
$$$$
\left.+\int_{0}^{\mathrm{Q} / x} \frac{\alpha^{2}}{y} f\left(\frac{\alpha x}{y}\right) g(\alpha) d \alpha\right]<0,
$$$$
\frac{\partial^{2} E\left(\Pi_{s c}\right)}{\partial x \partial Q}=\frac{\partial^{2} E\left(\Pi_{s c}\right)}{\partial Q \partial x}
$$$$
=\left(p+\pi_{m}\right) \int_{Q / y}^{\infty} \frac{Q}{x^{2}} g\left(\frac{Q}{x}\right) f(\varepsilon) d \varepsilon .
$$

Hessian matrix is as follows:

$$
H=\left(\begin{array}{ll}
\frac{\partial^{2} E\left(\Pi_{s c}\right)}{\partial Q^{2}} & \frac{\partial^{2} E\left(\Pi_{s c}\right)}{\partial Q \partial x} \\
\frac{\partial^{2} E\left(\Pi_{s c}\right)}{\partial x \partial Q} & \frac{\partial^{2} E\left(\Pi_{s c}\right)}{\partial x^{2}}
\end{array}\right)>0
$$

\section{Acknowledgments}

This research was supported by the National Natural Science Foundation of China (no. 71102174, 71372019, and 71272058), Beijing Natural Science Foundation of China (no. 9123028), Beijing Philosophy and Social Science Foundation of China (no. 11JGC106), Specialized Research Fund for Doctoral Program of Higher Education of China (no. 20111101120019), Program for New Century Excellent Talents in University of China (No. NCET-10-0048, NCET-10-0043), Key Project Cultivation Fund of the Scientific and Technical Innovation Program in Beijing Institute of Technology of China (no. 2011DX01001), Excellent Young Teacher in Beijing Institute of Technology of China (no. 2010YC1307), and the Basic Research in Beijing Institute of Technology of China (no. 20102142013). The authors are grateful to the anonymous reviewers and editors for insightful comments and kind help.

\section{References}

[1] G. Li, M. Q. Liu, Z. H. Wang, and B. Z. Peng, "Supply coordination based on bonus policy in assembly under uncertain 
delivery time," Chinese Journal of Mechanical Engineering, vol. 26, pp. 293-303, 2013.

[2] B. Tomlin and Y. Wang, "On the value of mix flexibility and dual sourcing in unreliable newsvendor networks," Manufacturing \& Service Operations Management, vol. 7, no. 1, pp. 37-57, 2005.

[3] V. Babich, A. N. Burnetas, and P. H. Ritchken, "Competition and diversification effects in supply chains with supplier default risk," Manufacturing \& Service Operations Management, vol. 9, no. 2, pp. 123-146, 2007.

[4] M. Gümüs, S. Ray, and H. Gurnani, "Supply-side story: risks, guarantees, competition, and information asymmetry," Management Science, vol. 58, pp. 1694-1714, 2012.

[5] X. Hu, H. Gurnani, and L. Wang, "Managing risk of supply disruptions: incentives for capacity restoration," Production and Operations Management, vol. 22, pp. 137-150, 2013.

[6] V. Babich, "Vulnerable options in supply chains: effects of supplier competition," Naval Research Logistics, vol. 53, no. 7, pp. 656-673, 2006.

[7] B. C. Giri, "Managing inventory with two suppliers under yield uncertainty and risk aversion," International Journal of Production Economics, vol. 133, no. 1, pp. 80-85, 2011.

[8] M. Oberlaender, "Dual sourcing of a newsvendor with exponential utility of profit," International Journal of Production Economics, vol. 133, no. 1, pp. 370-376, 2011.

[9] A. Xanthopoulos, D. Vlachos, and E. Iakovou, "Optimal newsvendor policies for dual-sourcing supply chains: a disruption risk management framework," Computers \& Operations Research, vol. 39, no. 2, pp. 350-357, 2012.

[10] B. Tomlin and Y. Wang, "Pricing and operational recourse in coproduction systems," Management Science, vol. 54, no. 3, pp. 522-537, 2008.

[11] S. Cho and C. S. Tang, "Advance selling in a supply chain under uncertain supply and demand," Manufacturing \& Service Operations Management, vol. 15, pp. 305-319, 2013.

[12] S.-J. Deng and W. Elmaghraby, "Supplier selection via tournaments," Production and Operations Management, vol. 14, no. 2, pp. 252-267, 2005.

[13] T. Sawik, "Selection of supply portfolio under disruption risks," Omega, vol. 39, no. 2, pp. 194-208, 2011.

[14] T. Sawik, "Selection of a dynamic supply portfolio in maketo-order environment with risks," Computers \& Operations Research, vol. 38, no. 4, pp. 782-796, 2011.

[15] C. S. Tang, "Perspectives in supply chain risk management," International Journal of Production Economics, vol. 103, no. 2, pp. 451-488, 2006.

[16] G. Abhijeet, D. Samir, and K. Roy, "Supply chain risk management: present and future scope," International Journal of Logistics Management, vol. 23, pp. 313-339, 2012.

[17] K. B. Hendricks and V. R. Singhal, "Association between supply chain glitches and operating performance," Management Science, vol. 51, no. 5, pp. 695-711, 2005.

[18] K. B. Hendricks and V. R. Singhal, "An empirical analysis of the effect of supply chain disruptions on long-run stock price performance and equity risk of the firm," Production and Operations Management, vol. 14, no. 1, pp. 35-52, 2005.

[19] P. R. Kleindorfer and G. H. Saad, "Managing disruption risks in supply chains," Production and Operations Management, vol. 14, no. 1 , pp. 53-68, 2005.

[20] A. Oke and M. Gopalakrishnan, "Managing disruptions in supply chains: a case study of a retail supply chain," International Journal of Production Economics, vol. 118, no. 1, pp. 168-174, 2009.
[21] B. Tomlin, "Impact of supply learning when suppliers are unreliable," Manufacturing \& Service Operations Management, vol. 11, no. 2, pp. 192-209, 2009.

[22] B. Maddah, M. K. Salameh, and G. M. Karame, "Lot sizing with random yield and different qualities," Applied Mathematical Modelling, vol. 33, no. 4, pp. 1997-2009, 2009.

[23] H. Gurnani, "Optimal lot-sizing policy with incentives for yield improvement," IEEE Transactions on Semiconductor Manufacturing, vol. 18, no. 2, pp. 304-308, 2005.

[24] C. A. Yano and H. L. Lee, "Lot sizing with random yields: a review," Operation Research, vol. 43, pp. 311-344, 1995.

[25] H. Gurnani, R. Akella, and J. Lehoczky, "Supply management in assembly systems with random yield and random demand," IIE Transactions, vol. 32, no. 8, pp. 701-714, 2000.

[26] H. Gurnani and Y. Gerchak, "Coordination in decentralized assembly systems with uncertain component yields," European Journal of Operational Research, vol. 176, no. 3, pp. 1559-1576, 2007.

[27] Y. Gerchak and Y. Wang, "Revenue-sharing vs. wholesaleprice contracts in assembly systems with random demand," Production and Operations Management, vol. 13, no. 1, pp. 23-33, 2004.

[28] Q. Li and S. Zheng, "Joint inventory replenishment and pricing control for systems with uncertain yield and demand," Operations Research, vol. 54, no. 4, pp. 696-705, 2006.

[29] M. G. Güler and T. Bilgiç, "On coordinating an assembly system under random yield and random demand," European Journal of Operational Research, vol. 196, no. 1, pp. 342-350, 2009.

[30] M. G. Güler and M. E. Keskin, "On coordination under random yield and random demand," Expert Systems With Applications, vol. 40, pp. 3688-3695, 2013.

[31] O. Tang, S. Nurmaya Musa, and J. Li, "Dynamic pricing in the newsvendor problem with yield risks," International Journal of Production Economics, vol. 139, no. 1, pp. 127-134, 2012.

[32] I. S. Bakal and E. Akcali, "Effects of random yield in remanufacturing with price-sensitive supply and demand," Production and Operations Management, vol. 15, no. 3, pp. 407-420, 2006.

[33] M. R. Singh, C. T. Abraham, and R. Akella, "Wafer design problem in semiconductor manufacturing for reliable customer service," IEEE Transactions on Components, Hybrids, and Manufacturing Technology, vol. 13, no. 1, pp. 103-108, 1990.

[34] Y. Gerchak, Y. Wang, and C. A. Yano, "Lot sizing in assembly systems with random component yields," IIE Transactions, vol. 26, no. 2, pp. 19-24, 1994.

[35] H. Gurnani, R. Akella, and J. Lehoczky, "Optimal order policies in assembly systems with random demand and random supplier delivery," IIE Transactions, vol. 28, no. 11, pp. 865-878, 1996.

[36] S. S. Sana, "An economic production lot size model in an imperfect production system," European Journal of Operational Research, vol. 201, no. 1, pp. 158-170, 2010.

[37] M.-A. Louly and A. Dolgui, "Optimal time phasing and periodicity for MRP with POQ policy," International Journal of Production Economics, vol. 131, no. 1, pp. 76-86, 2011.

[38] Y. He and J. Zhang, "Random yield supply chain with a yield dependent secondary market," European Journal of Operational Research, vol. 206, no. 1, pp. 221-230, 2010.

[39] W. Shih, "Optimal inventory policies when stock outs result from defective products," International Journal of Production Research, vol. 18, no. 6, pp. 677-686, 1980.

[40] J. W. Friedman, Game Theory with Application to Economics, Oxford University Press, New York, NY, USA, 1986. 


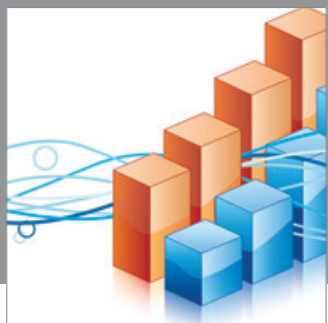

Advances in

Operations Research

mansans

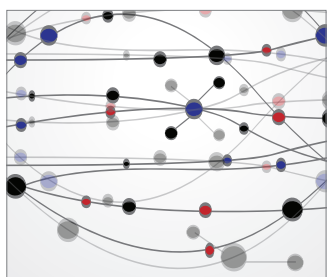

The Scientific World Journal
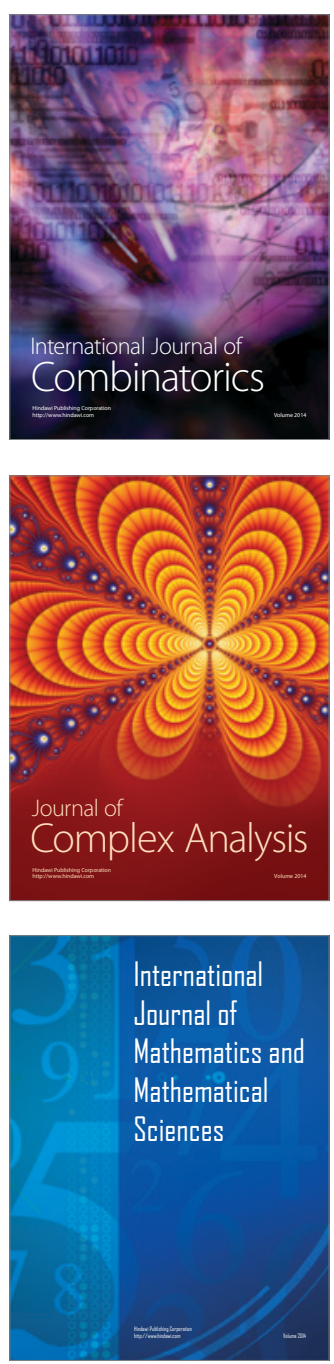
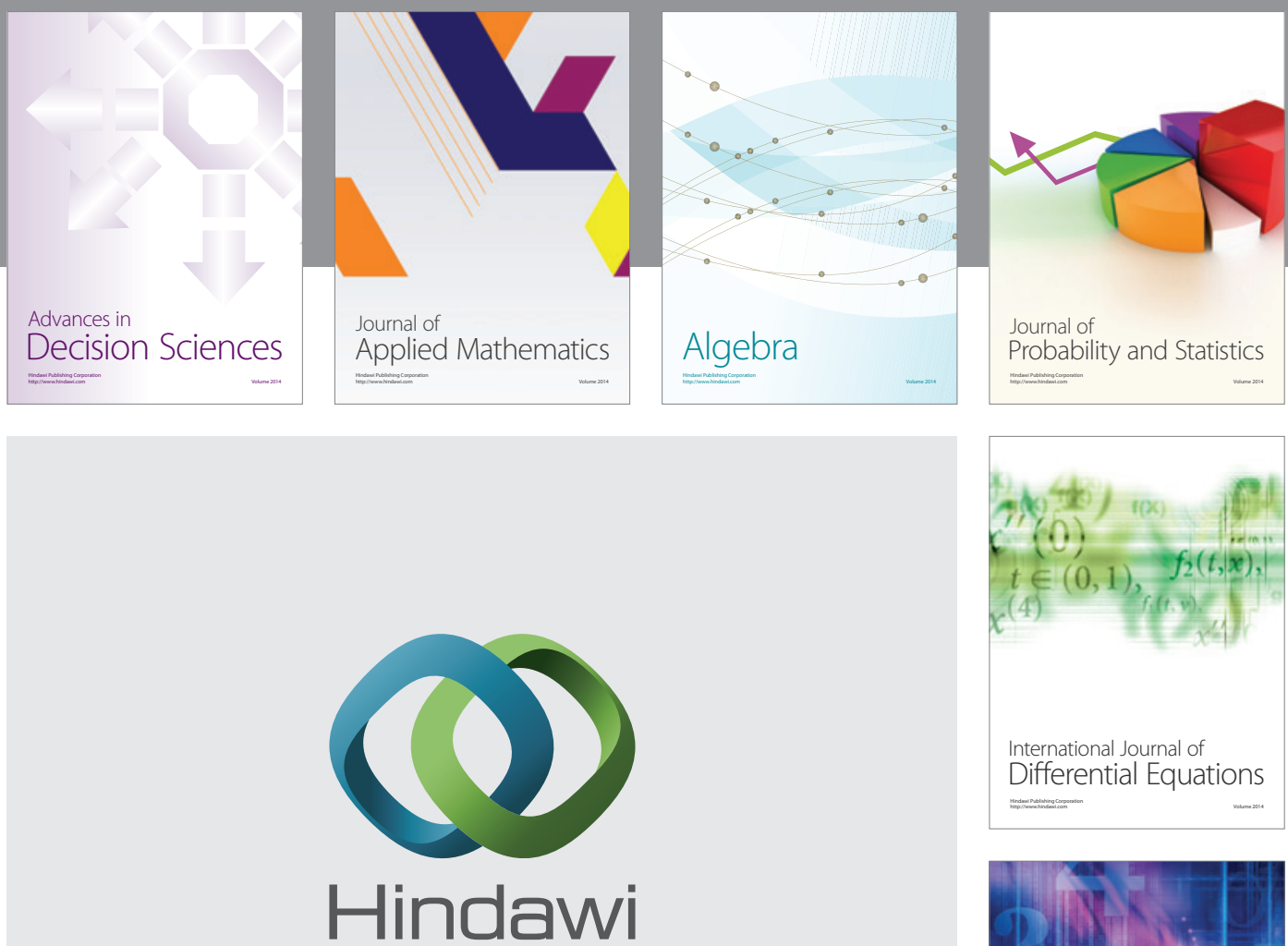

Submit your manuscripts at http://www.hindawi.com
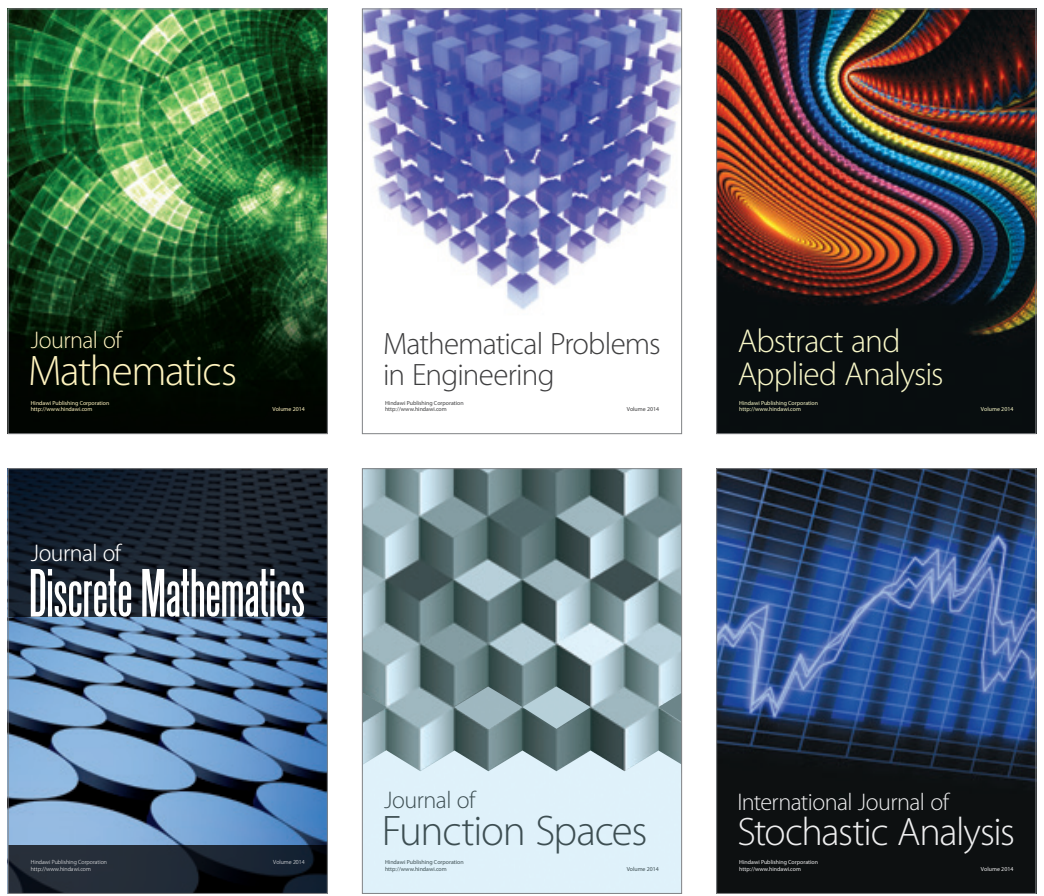

Journal of

Function Spaces

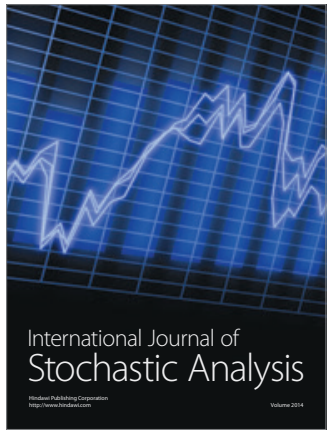

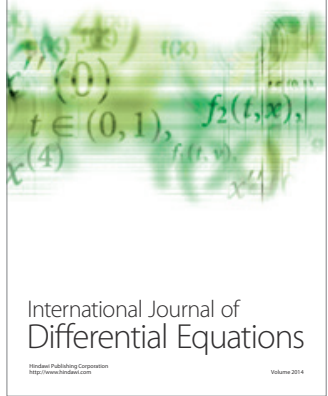
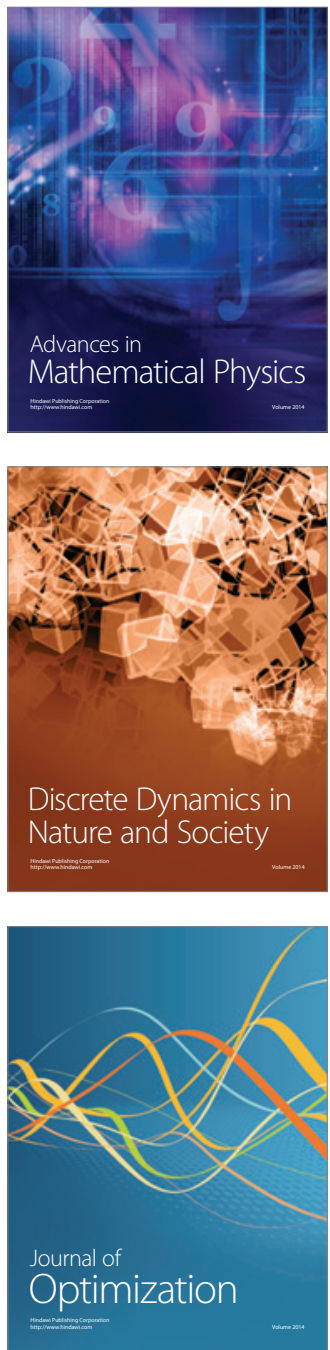